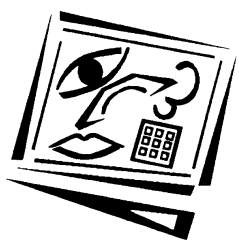

\title{
Internet tools for language learning: University students taking control of their writing
}

\author{
Mark A. Conroy \\ University of New England
}

\begin{abstract}
Many excellent corpus-based language learning resources (e.g., concordancers) have been freely available on the Internet for some time. Google assisted language learning (GALL) is also gaining increasing acceptance. These tools are a potential resource for English as an additional language (EAL) university students who want to independently improve their academic writing. However, many Australian universities have been remarkably slow to integrate these tools into English language support operations. In this study, Australian EAL university students were trained in Internet-based tools and techniques for language learning and subsequently surveyed on their attitudes and behaviour. Students' competence in using the tools and techniques to correct errors in their writing was also measured. The results revealed that students are enthusiastic and reasonably competent users of Internet-based tools and techniques for independent language learning. It is argued that Internet-based corpus tools and techniques are undervalued by Australian universities, but could be promoted and used to support EAL university student writers.
\end{abstract}

\section{Background}

Most Australian universities have significant and growing numbers of English as an additional language (EAL) students. In 2006 at the 39 Australian universities, 26\% of all enrolments (272 870 students) were international students (Department of Employment Education and Workplace Relations, 2008), who typically originate from countries where English is not the main language (e.g., China and India). As an illustrative example, in 2006 the University of South Australia, a medium-sized Australian university, had 4493 international EAL students on its Australian campuses, accounting for $17 \%$ of all Australian campus students at that university, rising to 5891 in 2008, an increase of 31\% over 2006.

Many EAL university students in Australia require assistance with their English language and academic writing to successfully complete their studies. In some cases this assistance is sufficient to foster students' English language development, but not always. In fact, claims have emerged that significant numbers of international EAL students not only enter, but also graduate from Australian universities with an inadequate standard of English language proficiency (Birrell, 2006). Acknowledging the importance of monitoring and developing the English language of students, at least one university (e.g. University of South Australia, 2007), has recently commissioned research into the English language proficiency of EAL university students and at least one university has implemented innovative policies in this area (e.g. Dunworth, 2009b). In addition, the Australian Government (Department of Employment Education and Workplace Relations, 2008) has recommended English language 
guidelines, published in the report: Good Practice Principles for English Language Proficiency for International Students in Australian Universities. At least 18 Australian universities have also recently set up post-entry English language assessment tools to ensure that students with inadequate English language skills are identified early in their studies so that they can be assisted (Dunworth, 2009a). In sum, most Australian universities accept that a significant number of their EAL students require assistance in developing their English language proficiency for academic life. Hence, monitoring language proficiency and providing language support, usually in the form of writing support, are priorities for many, if not most Australian universities.

\section{English language support at Australian universities}

English language and writing support for Australian EAL university students is typically provided by generic language support staff, usually centrally located in language and learning support centres. These staff typically provide assistance in the form of workshops, individual consultations, web resources and handouts. According to the Association for Academic Language and Learning, the professional association representing many tertiary language and learning advisers in Australia, in 2008 the total number of staff at language and learning support units at Australian universities was 363, with an average institutional staff to student ratio of 1:2890 (range: 1:900 to 1:7500) (see Department of Employment Education and Workplace Relations, 2008). Obviously, these ratios include all students, many of whom do not require or seek out language support. However, since EAL students account for $26 \%$ of all university enrolments in Australia, and it is likely that of these many university students do seek or require assistance, the workload on language support staff is high. Clearly, a very small number of staff have to support a very large number of students.

Centrally located language support staff also typically have to support students across a diverse range of academic disciplines. This diversity of student backgrounds is associated with a diversity of language needs, at both the discourse and lexical level. Given this diversity and complexity, it is generally accepted that a "one size fits all" approach to academic literacy does not work well, and a discipline-based or genrebased approach which targets teaching and learning of the specialist vocabulary and discourse patterns of a student's area of study is the most effective basis upon which to improve university students' communication skills (Swales, 1990).

Individual consultations between language support staff and EAL students are a common method of enhancing EAL students' academic literacy at Australian universities, and are seen as a valuable strategy for several organisational and pedagogical reasons (Chanock, 2007). One advantage is that language support can be tailored to the specific discourse needs of each student. However, individual consultations in certain formats have been criticised (Huijser, Kimmins \& Galligan, 2008; Stevenson \& Kokkinn, 2007). This is because in consultations, students, and to some extent the broader university, typically expect language support staff to edit writing, correct errors and provide prescriptive and didactic advice to students about their language problems (Huijser, et al., 2008; Stevenson \& Kokkinn, 2007). From a pedagogical perspective it is well established that L2 error correction is best done in conjunction with students' own reformulations (e.g. Ferris, 2002), rather than through overt corrections by teachers, and many language support staff choose this method of teaching. However, this approach to writing support in individual consultations can be even more time-consuming than simple "marking and correcting". Another possible drawback of individual consultations is that some students can become dependent on 
repeated individual consultations with language advisers (Hutchings, 2006), which can result in an excessive burden on staff and a lack of independence in students. Other modes of language support also exist. Some university divisions employ dedicated language and study skills support personnel embedded within their disciplines. However, usually this is a single person who services the needs of hundreds of students. Of course the academic staff in each discipline might also provide some language and writing assistance, although this is likely to be limited.

\section{Learning styles at Australian universities}

Set against these typical practices of university language support staff are the institutional and pedagogical goals of universities. Almost all Australian universities promote relatively non-didactic and student centred teaching practices which foster students' independent thinking and learning along the lines advocated by Biggs (2003) and others. These approaches are made explicit in various mission statements and statements of teaching philosophy, criteria for staff teaching awards, and statements about graduate qualities.

In sum, Australian universities face a complex task: How to efficiently support the often significant L2 language and writing needs of a large and growing cohort of EAL students, in a way which fosters students' independence and adheres to universities stated educational goals. This research addresses this question by investigating how EAL students might use the Internet and Internet-based corpora together with corpus search tools (concordancers) and search engines (Google) to independently monitor and improve the quality of their academic writing, and independently develop their second language proficiency.

\section{Corpus-based language learning}

Corpora and concordancers have been utilised in second language classrooms for at least 20 years. A corpus is essentially a large database of texts. Examples include the British National Corpus and the Brown Corpus. A concordancer is software which extracts instances of a specific search word or search phrase from a corpus and presents these instances in their immediate linguistic context. The output is referred to as a concordance and can be used by language learners to learn about specific grammatical and lexical patterns in the L2 in a form of data-driven learning (Cobb, 1997; Gaskell \& Cobb, 2004; Johns, 1994; Kaur \& Hegelheimer, 2005; Milton, 2006; Shei, 2008a, 2008b; Sun, 2003; Todd, 2001). According to Kaur and Hegelheimer (2005, p. 290), this type of data-driven learning can "help [students] become autonomous learners and also provide them the opportunity to act as researchers". Johns (1994) was one of the first to recognise the potential of data-driven language learning and advocated this approach over several decades. Data-driven approaches to language learning seem to be a sensible way to foster the independence (Chambers 2005), criticality and problem solving skills of university students.

Until recently corpus techniques for second language learning have often been used in teacher-driven contexts. Concordancing was also originally limited to computer labs in language centres and learners were often unable to access the corpora outside the lab. More recently however, many excellent corpora have become freely available on the Internet, and several freely accessible websites have been set up to enable corpus analysis and concordancing by L2 learners (e.g. Tom Cobb's Compleat Lexical Tutor at 
the University of Quebec at http://www.lextutor.ca/ and Virtual Language Centre at Hong Kong Polytechnic University at http://vlc.polyu.edu.hk/). Consequently, according to Gaskell and Cobb (2004, p. 306) the availability of these Internet-based corpora and concordancers have "now made all the world a concordancing lab", and the possibility of learners taking control of the technology and using concordancing for independent, data-driven language learning is increasingly being explored (e.g. Chambers, 2005).

One of the first studies to address the question of whether learners could use concordancers independently was conducted by Cobb (1997), who found that university pre-entry learners of English as a second language (ESL) could use concordancing to learn vocabulary. More recently, other researchers have obtained similar findings about the benefits of corpus analysis and concordancing for learners (e.g. Horst, Cobb \& Nicolae, 2005; Milton, 2006). Horst, Cobb and Nicolae set up an elaborately designed study, using concordancers in pre-university intermediate and high-intermediate level ESL classrooms, to investigate the learning of new words. They allowed learners to select which academic words they learned and logged their behaviour. It was found that learners could learn new words through a process of induction by entering words into a concordancer and using the rich semantic, syntactic and collocational information from the multiple sentence contexts in the concordance output.

Corpus-based techniques can be used for learning a range of lexical and grammatical phenomena. Most studies have examined vocabulary learning (e.g. Kaur \& Hegelheimer, 2005; O'Sullivan \& Chambers, 2006), but several other studies have examined the learning of lexico-grammar (e.g. Lee \& Swales, 2006; Todd, 2001), and increasingly also grammar (Gaskell \& Cobb, 2004; Liu \& Jiang, 2009; Yoon \& Hirvela, 2004). O'Sullivan and Chambers found that learners of L2 French could correct 19 of 25 preposition errors, and 22 of 28 word choice errors after instruction in corpus techniques. Lee and Swales found that EAP learners could use corpus techniques to learn "for" + verb-ing structures. Liu and Jiang also found that learners could acquire lexico-grammatical patterns (i.e. "keep" + verb-ing). Todd found that learners could independently induce correct grammatical and lexical patterns, and that they could use this knowledge to self-correct errors in their own writing. According to Todd, a learner could correct an error such as "It is capable taps all kinds of parts" by noticing that "capable" is usually preceded by the verb to be and followed by a verb + ing and reformulate the fragment to: "It is capable of tapping all kinds of parts". Other studies of grammar learning have, however, reported only partial success (Gaskell \& Cobb, 2004; Yoon and Hirvela, 2004).

Corpus-based language learning techniques have long been considered suitable for English for academic purposes (EAP) and English for specific purposes (ESP) (e.g. Flowerdew, 2003; Mudraya, 2006; Thursten \& Candlin, 1998; Yoon \& Hirvela, 2004), and for learning specialist technical and academic vocabulary (Cobb, 1997). The use of these techniques can reduce the amount of time needed to acquire academic vocabulary (Kaur \& Hegelheimer 2005). In one Australian EAP context, Cargill and Adams (2005) trialed the use of concordancing by agriculture PhD students. Students were encouraged to create their own discipline specific corpus and use it with concordance software to enhance their writing skills. Students were initially very positive about using this technique and thought it was potentially very useful. Similarly, in a study of law students at a Hong Kong university, Hafner and Candlin 
(2007) trialed corpora and concordancers and found that initial take-up of the techniques by students was quite good (21\% for 1st year law students and $40 \%$ for 2 nd year law students). Clerehan, Kett and Gedge (2003) also reported on the introduction of a web resource, including concordancing tools, to undergraduate IT students at an Australian university, and found moderate levels of student interest in concordancing.

One of the advantages of corpus language learning is access to context. For some time, there has been widespread acceptance in the literature of the advantage of learning a word in multiple contexts, compared to learning a word in a single context (e.g. Nation, 2001). Words often have "fuzzy" meanings and the exact meaning of even a simple word can sometimes be hard to pin down (Schmidt, 2000). Academic vocabulary, which is often abstract or "fuzzy", can be particularly troublesome for L2 speakers. Hence, dictionary definitions, which typically provide only limited context, should be considered only as part of the solution to the problem of word learning, and definitions must be supplemented by contextual information such from as extensive reading or corpus analysis. Along these lines, Prince (1996) suggested that a combination of translation definitions and contextual information might be the best method of learning new words in an L2, resulting in word knowledge that is more transferable to new contexts.

Of course, extensive reading as a means of providing contextual information can be time consuming. However, corpus analysis can provide a "short cut" to contextual information about register, and lexical and semantic associations. Kaur and Hegelheimer (2005) compared the use of online dictionaries and concordancers, looking for evidence of transfer of word knowledge to new sentence contexts. Intermediate level ESL students were asked to learn a list of academic words and integrate these words into their writing. The treatment group, which used a concordancer and an online dictionary, was compared to a control group which only used an online dictionary. Even though the treatment group did not use the concordancer as much as expected, it still improved more than the control group. Thus, even a small amount of concordancing resulted in better acquisition of academic word knowledge and the transfer of this knowledge into a writing task. This outcome is consistent with Cobb's (1999 p. 18) view that "lexical knowledge acquired from a definition tends to remain inert and untransferable to novel contexts". Importantly though, Cobb and others (Horst, Cobb \& Nicolae 2005) have added that lexical knowledge obtained from a dictionary can in fact be transferred to novel contexts, if the dictionary is consulted for confirmation of knowledge already obtained from the contextually rich output of a concordance.

\section{Student attitudes to corpus-based language learning}

Several studies of L2 English learners (Liu \& Jiang, 2009; Yoon \& Hirvela 2004) and L2 French learners (Chambers, 2005; O'Sullivan \& Chambers, 2006) have reported positive attitudes to corpus-based language learning techniques. Yoon and Hirvela reported that $93 \%$ of advanced learners and $100 \%$ of intermediate learners found the techniques useful for learning about the usage of vocabulary and phrases, while $54 \%$ and $88 \%$ respectively found the techniques useful for learning the meaning of words. Overall, learners felt strongly that corpus techniques can help them improve their writing. Liu and Jiang also reported that 39\% of learners said they "learnt a lot" from corpora, 52\% would use corpora in the future, and $54 \%$ said that after using corpus techniques they had realised that context was an important factor when learning lexico-grammar. 
Of course, not all learners find corpus techniques useful. Cargill and Adams (2006) reported that although research students were initially positive about using corpus techniques for improving their writing, surprisingly, they indicated hardly any interest in using the techniques when they were surveyed 8 months later. Similarly, Hafner and Candlin (2007) reported a similar drop off in interest and use by law students, and not all students used the corpus tools and techniques for language learning; many students used the specialist corpora only for accessing legal information relevant to their writing, and not for purely language related purposes. The news is not all bad though. Gaskell and Cobb (2004) found that 7 of their 20 participants continued to independently use concordancing after initial instruction and feedback. Reasons for low uptake of corpus-based language learning include insufficient training (Hafner \& Candlin 2007), and individual preferences.

\section{Limitations of corpus-based language learning}

One possible criticism of independent corpus-based approaches to L2 learning is that an L2 writer might not know that his/her usage is non-standard or faulty, and thus be unable to self-monitor. While this potential difficulty has been acknowledged in the literature, many researchers admit that it can be avoided, or is of relatively minor importance, and have argued that using corpora and concordancing is a legitimate way for students to "check their intuitions" about the appropriateness of their L2 writing (Hafner \& Candlin, 2007; O'Sullivan \& Chambers, 2006). Milton (2006, p. 129) for example, argues that corpus-based resources "can partly compensate for FL writers' lack of L2 intuition and for their limited exposure to the target language and its cultural contexts". Others have positioned these techniques as a form of "learning by discovery" (Lee \& Swales 2006) and therefore as an effective tool for independent data-driven learning.

\section{Google-assisted language learning}

More recently, the Internet and search engines such as Google have also been considered as resources for independent language learning for advanced L2 learners (Chinnery 2008; Guo \& Zhang, 2007; Hafner \& Candlin, 2007; Milton, 2006; Shei, 2008a, 2008b; Yoon and Hirvela, 2004). The Internet is a vast database of language: millions of documents, billions of words. In 2006, Google indexed 25 billion web pages (Guo \& Zhang, 2007). Surely here is a resource ripe for exploitation by language learners. Shei (2008a, 2008b) describes how a non-native speaker might learn about the typical phraseological patterns in native-speaker discourse using Google searches from frequency analyses of extended collocations (combinations of up to four words). Shei (2008a) argues that this technique could be used in second language teaching, and perhaps alluding to the uniqueness of the approach, has extended the meaning of the acronym GALL (Google assisted language learning), first coined by Chinnery (2008), to include corpus-based language learning using Google.

Milton (2006) also advocates the use of intelligent Google searches by students to edit and refine their writing, and has developed a resource-rich feedback tool (http:/ / mws.ust.hk/cmw/index.php) which plugs into the toolbar of MS Word. This tool links to a suite of Internet resources including Google, online corpora, concordance software, online dictionaries, thesauruses, encyclopedias, and an online English grammar guide. Using this tool, students can check and edit specific sections of their text for grammatical and lexical appropriateness by referring to evidence from 
authentic texts. Milton describes how a learner who wrote "It enhances the controlling and decision-making of management" was directed by an instructor to Google and corpus searches to notice that "enhance" is a transitive verb which tends to collocate (combine) with "ability". The learner then reformulated the sentence to "It enhances the controlling and decision-making ability of management". Thus, by inspecting frequently occurring word combinations the learner has improved his/her writing in a data-driven learning process and, according to Milton (p. 131), "helped the student to acquire the means and confidence to self-edit in the future".

When given a choice, many students appear to prefer using Google to concordancers. Sun (2007) found that learners preferred using Google searches to a concordancer to find appropriate patterns of language usage. Hafner and Candlin (2007) also found in their study that several of their L2 English university law students preferred using Google searches over using a specialist legal corpus and concordance software when drafting professional legal documents in English. The important point that several researchers have made (e.g. Shei, 2008a, 2008b) is that Google searches of the Internet can produce much richer output for very specific search queries than any standard corpus.

The abundance of data and the task of sifting through enormous amounts of language are in fact two of the problems associated with using Google, and several studies have reported that learners can get overwhelmed. Guo and Zhang (2007) have attempted to 'clean up' the output of a Google search so that language students might more easily make sense of it. Similarly, WebCorp (http://www.webcorp.org.uk/), an Internet search tool, developed in association with Birmingham City University, which assembles concordances from the Internet, also attempts to provide relatively userfriendly output which could be used by second language learners.

In sum, Google appears to hold great potential for independent language learning, as highlighted by Shei (2008b, p.23): "It [Google] remains a constant companion to the learner in the absence of the tutor. All the TESOL teacher has to do is to show the learner how to use this versatile tool". Gaskell and Cobb (2004) also pointed out the potential for learner-driven online corpus consultation to reduce the burden on language instructors and advisers, while Milton (2006, p. 125) believes that encouraging learners to use online corpora and Google for language learning and writing assistance "can help relieve teachers of the need to act as proofreading slaves". Similarly enthusiastic about the as yet unrealised potential of GALL as a language learning tool are Bhatia and Ritchie (2009, p. 547), who claim that "the application of Google for language learning has just begun to be tapped".

\section{Research questions}

Clearly, GALL and online corpora are potentially useful for EAL university students who want to improve their English language. However, it appears that only a few studies, only in specific academic disciplines, (e.g. Hafner \& Candlin, 2007) have investigated corpus-based, data-driven, independent language learning as a means of supporting the writing of L2 university students. Thus, the purpose of the present study is to investigate EAL university students' use of, and attitudes towards, Internetbased resources which facilitate independent language learning. Firstly, it is not known to what extent Internet-based tools for language learning are promoted or used as a mean of enhancing their EAL students' English language proficiency. Thus, the 
first research question in this study addresses this issue. The five remaining research questions were adapted from Gaskell and Cobb's (2004) study and extended to investigate the use of Google searches for writing improvement. The questions were:

1. Do Australian universities promote the use of Internet-based tools for independent language learning by EAL students?

2. Do students consider concordancing a useful activity for language learning and writing improvement?

3. Do students consider Google searches useful for language learning and writing improvement?

4. In what ways do students use concordancers and Google for language development and writing improvement?

5. Can students use concordances and/or Google output to successfully correct their errors?

6. Will students use concordances independently following training?

\section{Methodology}

\section{Participants}

Participants were EAL students enrolled at the University of South Australia, and advanced EAL learners in a pre-entry English language program at Adelaide University. Four groups received instruction in Internet-based language learning tools and techniques. The groups were:

1. A group of 110 students enrolled at an Australian university who were studying a diverse range of courses and who took part in a 1 hour training course of Internetbased corpus techniques (UNI group). This training was provided as part of a set of study skills workshops offered bi-annually to all EAL students at the university.

2. A group of 26 EAL students enrolled at an Australian university and studying a four week introductory academic program just prior to entering their degree programs. Students were from a range of disciplines. Most (24) of these students were postgraduates (IAP group).

3. A group of 15 undergraduate EAL students studying a 13 week course in English language as part of their degree. Many of these students were studying either because they personally perceived they needed to further improve their English language skills, or because they were identified by the university as having inadequate English language skills for academic study and directed to enroll in the course (ELA group).

4. A group of 14 undergraduate EAL students studying in an intensive university preentry English for academic purposes course (EAP group).

Groups 1, 2 and 3 had an IELTS score or equivalent of at least 6.0, and group 4 had a score of at least 5.5 .

\section{Procedure}

The four cohorts of students were trained in the use of Internet corpus-based techniques for language learning and writing improvement. The training, which was provided by the researcher, consisted of between 1 and 4 hours of instruction in concordancing, Google search techniques, and the use of online dictionaries. Each 
group received the following amount of instruction, spread over between 1 and 4 sessions, according to their needs and the available time.
UNI group: 1 hour
IAP group: 2 hours
ELA group: 2 hours
EAP group: 4 hours

The Internet tools covered in the research were:

- Virtual Language Centre at Hong Kong Polytechnic University http: / / vlc.polyu.edu.hk/

- Tom Cobb's Compleat Lexical Tutor at the University of Quebec http:// www.lextutor.ca/

- Google http://www.google.com/

- Online dictionaries

Training consisted of an introduction to corpora, concordancers and GALL techniques. Students were initially taught that in order to become familiar with a word or phrase they need information about the words or phrases:

- Meaning (e.g. from a dictionary definition)

- Linguistic/structural context (What words typically surround the word or phrase?)

- Field of use/ semantic frame (e.g. Fillmore, 2006). In other words, in what discipline or broad topic area is the word/phrase typically used? Or even in what English dialect is the word / phrase typically used?

- Frequency (How often is the word/phrase used by native speakers?)

- Other family members of the word and their frequency (noun, verb, adjective, and adverb)

- Pronunciation (How do you say the word?)

Students were then given a range of problem-based exercises. Some examples of the instructional content are provided.

Students were taught how to discover standard verb + preposition collocations (e.g. bestow upon, adhere to) using Google and concordancers. Students were also directed to discover the subtle differences in usage between similar-looking phrases, such as the following:

- additional funding or additional funds or additional fund

- supplementary funding or additional funding or extra funding

- supplementary funds or additional funds or extra funds

- supplementary fund or additional fund or extra fund

Expanding on these examples, students were shown how Google could be used to uncover subtle patterns of phraseology. They were shown how the frequency of verb + adverb combinations in standard English (e.g. focus strongly vs. focus deeply) can vary.

This led to the Google search output represented in Figure 1 and Figure 2. Students' attention was directed to the following features of the output: 


\begin{tabular}{|c|c|}
\hline "locuses deeply. Google Search. Windows Internet Explorer & E. \\
\hline 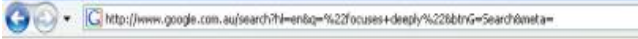 & $v+x$ wew seard \\
\hline 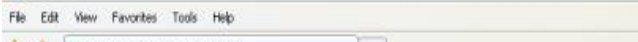 & \\
\hline 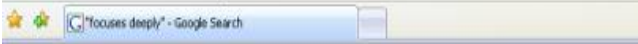 & Q. $0 \cdot \theta \cdot \partial_{\text {pase }} \cdot \theta_{\text {rosk }} \cdot$ \\
\hline Web Imagea Mape thewa Vidoo Gmail moen, & $\underline{\text { Sign in }}{ }^{\wedge}$ \\
\hline Search Advanced Search & \\
\hline Search: $\odot$ the web $\bigcirc$ pages from Australia & \\
\hline Web & "focuses deeply". (0.03 seconds) \\
\hline
\end{tabular}

Tip: Save time by hitting the return key instead of clicking on "search"

\section{The EASE Program}

This 2 day module of The EASE Program focuses deeply on the keys to accepting

yourself, loving yourself and healing issues that create you to close your ...

theeaseprogram.com/index.php? session=modules\&

PHPSESSID $=65 f 6290$ e70 da940651c0692c558a1561 - 31k - Cached - Simllat pages

by Cats Grouped / Bookmarks - Open Information Systems Security Group

This site focuses deeply on exploiting buffer overflows and other vulnerabilities in

code, ... Gera insecure programming, This site also focuses deeply into ...

www. oissg.org/links/istbycats/Root/O/all_ items.html - 136k - Cached - Similar pages

by Alpha Grouped / Bookmarks - Open Information Systems Security Group

This site focuses deeply on exploiting buffer overflows and other .... Gera insecure

programming, This site also focuses deeply into programming errors and ...

www. oissg. org/inks/ist/allalpha/Root/0/all_items.htm/ - 128k- Cached - Similar pages

More results from www. oissg.org .

Amazon.com: Harriet Klausner's review of Three Mothers

THREE MOTHERS is a fascinating character study that focuses deeply into the

interrelated yet separate lives of three generations of English women...

WWW. amazon, com/review/R1Z4307EIXV019 - 108k - Cached - Similar pages

Figure 1: Google output for focuses deeply

\begin{tabular}{|c|c|}
\hline \multicolumn{2}{|l|}{ " "locuses strongly" Goozle Search - Windows Internet Fxplorer } \\
\hline 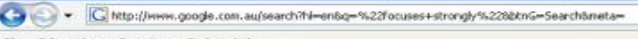 & 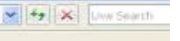 \\
\hline 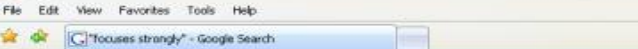 & \%. \\
\hline
\end{tabular}

Web Inages Maps News Video Gmail more.

GOOgle $\begin{gathered}\text { Hocuses strongty } \\ \text { Search: } \odot \text { the web o pages from Australia }\end{gathered}$

Web

Results 1 - 10 of about 20,000 for "focuses strongly"

Tip: Save time by hitting the return key instead of clicking on "search"

Plastics \& Rubber - SABIC Innovative Plastics focuses strongly on ...

China Trade Show news, China trade show news, China Exhibition news, Beijing trade

show news, Shanghai trade show news, Guangzhou trade show news, ..

e=18inewijt=38inid=030588ptid=528-37k-Cached - Similar pages

Developing a knowledge management strategy

This article presents a model that focuses strongly on the needs analysis activities

with staff, to drive a primarily bottom-up strategy, as follows: .

www. steptwo.com.au/papers/kmc_kmstrategyfindex. $h$ tml - 35k -

Cached - Similar pages

Get Involved I Habitat for Humanity Australia

... for Humanity is considered an important part of our 'sense of community' culture

which focuses strongly on facilitating home ownership for Australians. ..

www.habitatorg,au/get_involved/partnership/corporate.htm - 36k -

Cached - Similar page

TecTrends: Patent Law in India Focuses Strongly on R\&D

TecTrends Record for article Patent Law in India Focuses Strongly on R\&D.

Tec Trends Record for article Patent Law in India Focuses Strongly on R\&D
www.tectrends com/cgi/showan?an=00156762 - 17k - Cached - Similar pages

TecTrends: Article: Patent Law in India Focuses Strongly on R\&D...

Company Profiles \& Financials, Softbase: Article: Patent Law in India Focuses

Strongly on R\&D.
www.alacrastore.com/storecontenttectrends/156762 - $17 \mathrm{k}$ - Cached - Similar pages

Figure 2: Google output for focuses strongly 
- The frequency of focuses strongly is about 15 times more frequent than focuses deeply in standard native-speaker English.

- Focus deeply and focus strongly collocate most frequently with the preposition on.

- The semantic frame or field of use of focuses deeply involves mainly descriptions of plays, books, and movies, religion and spirituality, promotional material for alternative medicine, massage, etc, and promotional material for unconventional medicine and health.

- The semantic frame or field of use of focuses strongly overlaps with focuses deeply, but is much broader, but a Google search brings many more pages of government reports, business reports and from conventional education; page types which are not found from a search of the phrase focuses deeply.

Sometimes words that appear to be synonymous, and are even represented as synonyms in dictionaries, are not in fact true synonyms. Students were taught how to use concordancers and Google to distinguish between apparent synonyms (e.g. distinction or difference). A concordance or Google search will provide valuable contextual information which can accurately define the word's sense.

Students were asked to investigate contextual (lexical and syntactic) and semantic differences between words from the same family by using concordancing (e.g. associate vs. associated vs. association). Figure 3 illustrates a concordance output for associated.

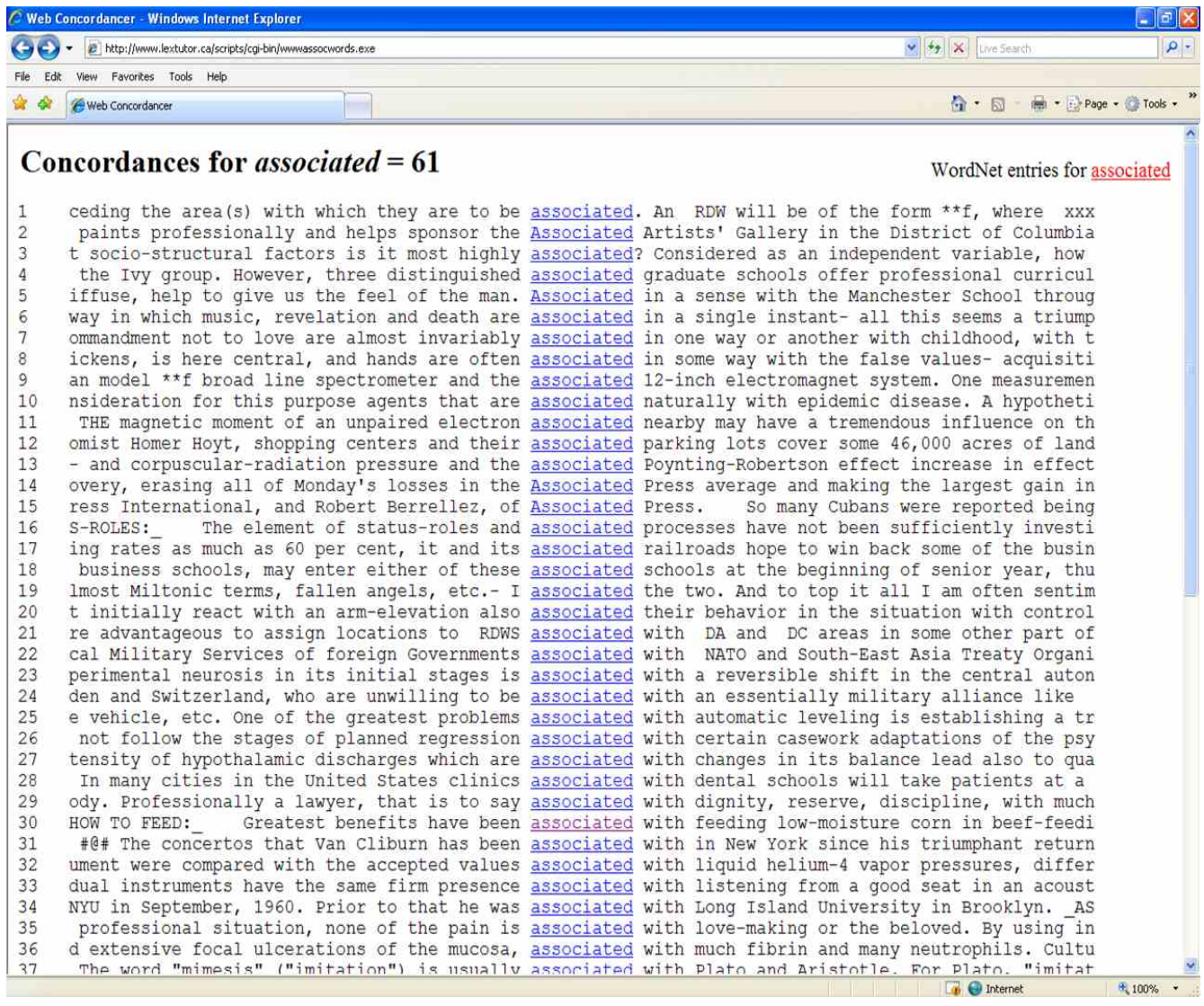

Figure 3: Concordance output for associated 
For example, on the basis of a concordance output, students were subsequently able to conclude that associated:

- frequently occurs as a past participle in a passive verb phrase

- frequently occurs as a past participle adjective (but less frequently than in a passive verb phrase)

- is frequently followed by with in a sentence

- often occurs in a scientific context

Some specific instructions were given to students about how to get the best linguistic data out of Google. One instruction was to go directly to at least the 10th hit page from a search. The reason for this action was that Google gives priority to the titles of web pages. So about the first 100 pages of a search output would typically include the search word or phrase only in a title or URL, and not necessarily in any sentence contexts. Students were also instructed to manually 'filter' out web pages from nonnative English speaking sources. These sources could often (but not always) be identified by a URL emanating from a country in which English is not the main language. Despite these instructions, some students still had difficulty extracting useful data from Google.

Finally in the training, students were encouraged to use concordancing, Google searches and online dictionaries to become their own "language researchers", in the hope that they would continue to use these tools and techniques independently. In order to structure their research, they were given a grid which contained the following criteria: meaning, frequency, syntactic class, collocations, semantic frame(s), example sentence(s).

When possible, students were also encouraged to act as "language researchers" and search for words and language patterns of relevance to their own interests. After between 2 and 4 weeks after the final training session, at which point the students would have had time to use the techniques on their own, they were anonymously surveyed on their attitudes to the training, and their use of Internet-based language learning techniques. The survey consisted of 7 discrete point questions and 2 text response questions.

Additionally, after the training, students in the ELA, IAP and UNI groups were given the opportunity to electronically submit a draft of up to two of their written university assignments. Using MS Word's review function (track changes and comments) the researcher identified, but did not correct, lexical and/or grammatical errors in each student's writing, and students directed students to independently use the Internet corpus-based techniques to correct these errors. Students were asked to subsequently submit a second draft of the original document for analysis and further feedback. The researcher then assessed the extent to which the previously identified errors had been corrected, thus evaluating each student's use of the techniques for independent error correction. Finally, the researcher sought qualitative feedback from each student about their experiences of using the techniques in a semi-structured interview. Students in the ELA group also had the opportunity to give further feedback if they wished in a journal they submitted at the end of their course, which was five weeks after the training, as part of their assessment for the course. 


\section{Results}

First, Research Question 1 is addressed. After that, the data from the four student groups are presented and discussed in relation to each of the remaining five research questions, followed by some general discussion. The overall survey response rate from all students who took part in the training was $32 \%$. The survey response rates for each group were:

1. UNI group: Survey responses were received from 15 students, equivalent to a response rate of $14 \%$.

2. IAP group: Survey responses were received from 18 students, equivalent to a response rate of $69 \%$.

3. ELA group: Survey responses were received from 6 students, equivalent to a response rate of $40 \%$.

4. EAP group: Survey responses were received from 14 students, equivalent to a response rate of $100 \%$.

\section{Research question 1: Do Australian universities promote the use of Internet- based tools for independent language learning by EAL students?}

There is little evidence of Australian universities' engagement with Internet corpus tools and techniques for language support. In a comprehensive summary and report on best practices in English language support at Australian universities (Department of Employment Education and Workplace Relations, 2008), not a single reference was made to deploying or encouraging the use of corpus-based methods of independent vocabulary learning (e.g. concordancing and GALL). The websites of all Australian universities' language and academic skills support units were surveyed in a desk audit, but little evidence could be found for the widespread use of Internet-based language tools: only 7 of the $39(18 \%)$ of Australian universities' language and academic skills support units showed clear evidence of using Internet corpora and concordancing tools. Where corpora and concordancers were referred to, this usually took the form of hyperlinks to external websites and advice on how to use them. It is possible of course that some of the other 32 universities promote the use of these tools and techniques, without advertising this on their websites.

\section{Research question 2: Do students consider concordancing a useful activity for language learning and writing improvement?}

Yes. The key finding from the surveys, semi-structured interviews and written journal feedback was that students found the Internet-based tools and techniques useful. First, $89 \%$ of survey respondents felt that using concordancers was either "very rewarding" or "somewhat useful". Second, all 53 survey respondents (100\%) found the training either "very useful" (68\%), or "somewhat useful" (32\%). Third, survey respondents found the tools and techniques useful and interesting to the extent that that most students $(87 \%)$ wanted further training.

Importantly, students' positive attitudes towards concordancing were reflected in their actual behaviour and intended behaviour, both of which changed substantially (see Figure 4). The proportion of students who used concordancing increased dramatically from $4 \%$ prior to training to $28 \%$ after training. Furthermore, when asked about their future intentions, an even greater proportion (36\%) indicated they would use a 
concordancer. Thus, they must have found concordancing useful and interesting, and were very interested in implementing corpus-based techniques for language learning.

Given that corpus-based language learning is known to be challenging for some learners (Yoon \& Hirvela, 2004), students were asked specifically about their experiences of using concordancers. Although some students reported some frustration with concordancing (9\%), most reported positive attitudes, with $89 \%$ saying concordancers were very rewarding $(36 \%)$, or somewhat useful $(53 \%)$. Thus, students did not find the tools and techniques especially difficult to use.

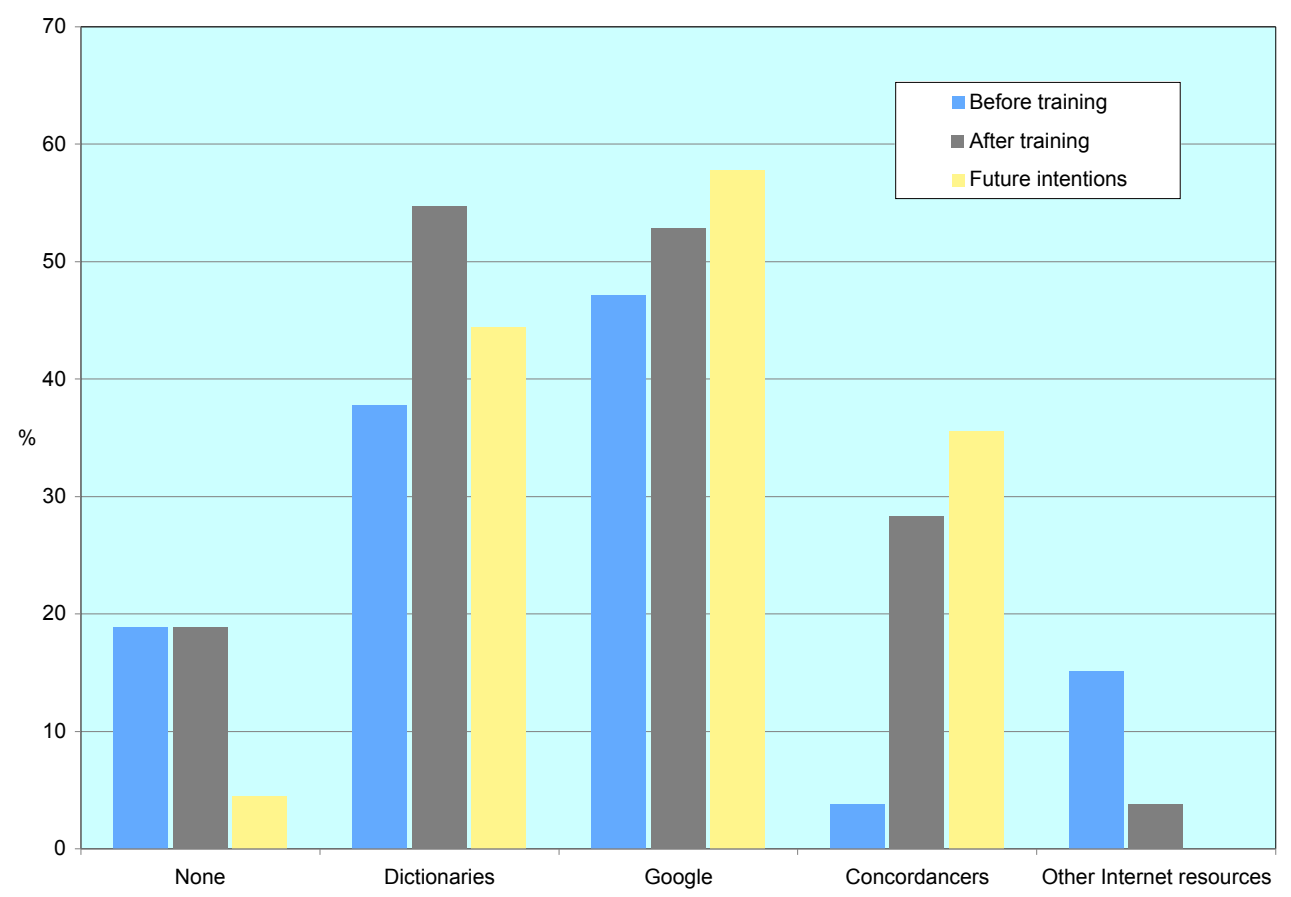

Figure 4: Students' use of Internet-based tools and resources before and after training (\%).

\section{Research question 3: Do students consider Google searches useful for language learning and writing improvement?}

Yes. First, a significant proportion $(47 \%)$ of students indicated that even before training they used Google searches for language learning (GALL). Presumably, then, many students must find it useful. Amongst the four participant groups, the UNI group reported the highest level of prior use of GALL $(60 \%)$, thus indicating that many EAL university students already use a form of GALL to improve their academic writing and learn language. Second, after training, students' use of GALL increased to $53 \%$, while their intended future use of GALL increased even further to $58 \%$.

Several students also commented on the usefulness of both Google and concordancing. These comments probably reflected the content of the instruction, which emphasised using a combination of both tools. Some illustrative comments from the survey were: 
Since I use Internet Tools (Concordancers and Google) everything is easier, fast and no mistake at all. Whenever I need to ensure my writing, I can trust these techniques $100 \%$ (UNI9)

I have to say I love this session. The reason is simple: it's because of it gives great help when I write stuffs and could check how I should use a simple word appropriately. (ELA1) Personally, this technique truly helps me to improve the quality of my writing! (ELA3)

Several students preferred Google searches rather than concordancing. During training, sometimes students found that they could not readily find concordance examples in the corpus they were using (e.g. the 1 million word Brown Corpus), a problem also noted by Gaskell and Cobb (2004), who argued for the use of larger corpora. Often this was frustrating for them, but when they were directed to a Google search they were often able to resolve the difficulty. The Internet is a much larger corpus than the corpora linked to concordancing websites, and thus provides a richer source of data. Students' preference for Google was also evidenced in the behaviour of the three students who took part in the error correction task. In that task, only one student used a concordancer to correct only one single error. All of the other error correction attempts used Google. Students' preference for Google, which is illustrated in the following comment, was noted in the survey and interview feedback:

I prefer using Google. After that if I couldn't figure it out I used another site.

Especially when I wrote some task I feel difficult where I am supposed to use particle or article preposition yeah especially articles and prepositions. Google is I can use it I can write all sentence you know all words. But in concordancer I can just write one word. (ELA3)

\section{Research question 4: In what ways do students use concordancers and Google for language development and writing improvement?}

Predictably, the survey revealed that the most frequently reported independent use of concordancers and Google was for help with writing their assignments (43\%). The small number of students (3) who took part in the error correction task makes answering this question in more detail difficult. However, some students' survey comments revealed some strategies, which were possibly representative of what other students did, and these are presented below. Some students, for example, used a combination of an online dictionary and concordancer or Google for strategically distinct purposes:

I used the dictionary to look up some terms and the concordancer to check on some of my phrases and sentences. (IAP12)

I mainly use Google to check my writing, or use online dictionaries to search for the words meaning when I am reading. (EAP7)

Other students appeared to use concordancers for lexico-grammatical purposes, determining word category choices while writing, for learning about preposition use, or passive and active choices, and for learning words:

I look for the family words on concordancers to choose the correct type of words (noun or verb or adjective, etc) (IAP13)

These two can help me to determine [...] whether I have appropriately combined words into standard phrases or I have used the correct preposition or I should use a passive and active sentence (ELA3)

References for my essay which I searched in Google helped me to get familiar with words and it is useful to use those words for some skills like writing and speaking. Therefore, they encourage me to analyse the words in sentences (IAP4) 
Some students apparently used Google searches to make sure their writing was more native-like, or was suitably academic in style:

While writing, met the strange word Internet tools can help to find one which is common used in Australia (EAP11)

These two can help me to determine which word that is frequently used by native English speakers (ELA3)

Writing an assignment to use Internet tools, check the grammar or other thing, such as whether or not academic (EAP10)

Many students used concordancers and Google to check their intuitions and monitor the correctness of their written assignments. This conclusion is consistent with previous research (e.g. Yoon \& Hirvela, 2007). Some illustrative comments were:

While writing an assignment, sometimes I forgot the correct words that I had to use it because I'm not sure whether or not my writing is correct (UNI9)

I use the internet tools when I am reading, and now I am writing my first assignment, I also will check it with internet based tools. (UNI12)

Some students used Internet tools and techniques also while reading $(21 \%)$ :

While reading when some words I found not familiar and do not know the meaning, I opt to look in the dictionary, or sometimes in Google search engine. (UNI13)

Finally, another student also explained how he used Internet tools and techniques to enhance the quality of his personal writing, and why that was important to him.

Sometimes I have to post my English writing on the Internet or something, my blog. If people find mistakes they think I have been to another country to improve my English they think maybe rubbish because they think I can't write correctly. I don't want people to think [that]. (ELA2)

\section{Research question 5: Can students use concordances and/or Google output to successfully correct their errors?}

Yes, probably. The small number of students who took part in the error correction task, which looked at students' ability to correct errors in their writing using Internet corpus-based methods, makes answering this question difficult. However, from the limited data it appears that students could more successfully correct their errors using Google than by using non-corpus-based techniques.

Five students took part in the error correction task - two from the ELA group, two from the IAP group and one from the UNI group. The two IAP students did not appear to fully engage with the techniques. One of these students was directed to correct 41 errors in a 12 page assignment draft using the Internet tools, but corrected only one error successfully. Another correction appeared to be the result of a plagiarised copy. Furthermore, this student did not change any of the identified errors from page 2 onwards of his draft; all remained unchanged. The second student appeared to initially engage with the tools in correcting the errors but then gave up. In total, she was directed to the Internet to correct 29 errors, and successfully corrected 6. However, after page 6 of her 10 page assignment draft, she appeared to have made no further attempts to correct errors. Since these two students did not appear to properly engage with the Internet-based tools and techniques as requested, they were excluded 
from the main analysis, although their refusal to engage is interesting (see section 5 for a discussion). Unfortunately it was not possible to interview these two students.

The remaining three students - two from the ELA group, one from the UNI group appeared to properly engage with the tools and techniques. In total, 45 errors were identified from these three students' written assignment drafts. Students used Google to try to correct 22 of these errors and were successful on 15 occasions, equivalent to a success rate of $68 \%$. Only one of the students used a concordancer to correct one error, which was also done successfully. Although students were asked to use corpus-based methods to correct the errors, they did not always do this, and students tried to correct another 22 errors without reference to Google or a concordance, but were successful on only 11 occasions, equivalent to a success rate of 50\% (See Table 1).

Table 1: Error correction attempts by students

\begin{tabular}{|l|c|c|c|c|c|}
\hline Student & $\begin{array}{c}\text { Total } \\
\text { errors }\end{array}$ & $\begin{array}{c}\text { Successful Google } \\
\text { error corrections } \\
\text { (attempts in } \\
\text { brackets) }\end{array}$ & $\begin{array}{c}\text { \% successful } \\
\text { Google error } \\
\text { corrections }\end{array}$ & $\begin{array}{c}\text { Successful non- } \\
\text { corpus-based error } \\
\text { corrections (attempts } \\
\text { in brackets) }\end{array}$ & $\begin{array}{c}\text { \% successful } \\
\text { non-corpus-based } \\
\text { error corrections }\end{array}$ \\
\hline ELA3 & 14 & $6(10)$ & 60 & $2(4)$ & 50 \\
\hline ELA4 & 23 & $6(8)$ & 75 & $7(15)$ & 47 \\
\hline UNI4 & 8 & $3(4)$ & 75 & $2(3)$ & 67 \\
\hline Total/Mean & 45 & $15(22)$ & 68 & $11(22)$ & 50 \\
\hline
\end{tabular}

\section{Research question 6: Will students use concordancers independently following training?}

Yes. The survey findings showed a substantial increase in the use of concordancers after training, as well as an intention to maintain this increased level of use into the future (see Figure 1). After instruction and only limited practice, 36\% of students stated that they would continue to use the techniques independently.

In addition to answering the research questions, a further finding about the novelty of the tools and techniques was made. Concordancing, and it seems also the GALL techniques covered in the training, were somewhat novel for most students. Only $4 \%$ of students indicated that they had used concordancers prior to the training. Almost half the students $(43 \%)$ indicated that prior to training they were only familiar with online dictionaries, while $19 \%$ indicated that they had not used Internet-based tools and techniques for language learning. Further evidence for the novelty of the techniques comes from the fact that almost all (87\%) of survey respondents wanted more instruction, even after instruction and practice. It didn't matter whether students had had one hour or several hours of instruction and guided practice in using the tools and techniques; they still wanted more. Several students' comments from the semistructured interviews confirmed the novelty of the tools and techniques. Two illustrative comments came from an ELA group student:

I honestly was quite surprised that aside from using online dictionary, which was the only thing I used in Internet to find the definition of word that I could not understand, there are other two ways that can be quite useful to analyse and editing our sentences in our writing for our essay or any other writing report/task. (ELA3)

I never know that the word could be checked by comparing the searching results [using Google]. (ELA4) 
More generally, when asked about all Internet-based tools, only $4 \%$ reported an intention not to use any of them into the future, which was dramatically lower than their pre-training and immediate post-training behaviour, where $19 \%$ were not using any Internet-based tools. Overall then, marked changes in students' use of Internetbased language learning tools, both qualitative and quantitative, and actual and intended, were recorded.

\section{Discussion}

These findings provide a snapshot of what some EAL university and pre-university students think of corpus-based independent language learning. The results reveal that a significant number of students are enthusiastic about using GALL and concordancing for second language learning and improving their academic writing. It was particularly surprising that many students already use GALL for language learning and writing support and that they preferred using Google searches to using a concordancer. The independent use of GALL by EAL university students at an English medium university appears to be thus far unreported in the literature, and presumably also remains unknown to most university administrators.

One important point needs be made with regard to the relatively low response rate (32\%) to the survey. It could be argued that the responses from roughly one third of participants who took part in the survey may not represent the attitudes and behaviour of the whole group who undertook training, and that the $68 \%$ who did not respond to the survey in fact had no interest in using Internet-based tools. In the context of the present study, however, this would be both an inaccurate and inappropriate conclusion. Firstly, it would be highly unlikely that all $68 \%$ of the nonrespondents were uninterested in the tools. Rather, it is likely that a proportion were interested, but for whatever reason did not respond to the survey, thus allowing the inference that the findings from the present study could plausibly represent the attitudes and behaviour of many more than the one third of participants who responded to the survey.

Secondly, even if only one third of participants were enthusiastic users of Internetbased tools, this would be highly significant in the context of the present study, because this finding appears to stand in contrast with the attitudes and behaviour of many university language support units and administrators. It is worth noting that university language support staff and management appear to be, at least on the surface, largely ignorant of, or at least ambivalent towards, the potential of these tools and techniques. Yet the findings here suggest that a significant number of EAL university students in Australia might either already use the tools and techniques, or be eager to start using them. If this is indeed the case, could those students who already engage with the tools, as well as the wider population of EAL university students, benefit from appropriate instruction, support and guidance in using these tools and techniques to improve their English language and academic writing?

One intriguing finding emerged from this study: many students are relatively naive users of the Internet. Although a surprising $47 \%$ of students had previously used GALL, other data from the survey and interviews indicated that students found the GALL techniques in the training quite novel and interesting. So it seems that while many students apparently use Google to support their L2 English writing, they might employ relatively crude or simplistic techniques, or even just use Google to search for 
word definitions from online dictionaries. Some evidence for this conclusion was that during the training sessions the researcher noted that students typically used crude and often inappropriate search strategies. Many students were, for example, unaware that they could use quotation marks to focus their search onto specific and uninterrupted word sequences (e.g. a verb and an associated preposition).

Also, during training it was observed that several students were often unable to search with sufficient critical skills to detect non-native texts and the non-standard usage often contained therein. These observations are all the more surprising given that students in this age group are often claimed to be sophisticated users of ICT. Thus, contrary to what is commonly believed, young university students, many from cultures with a strong uptake of computer technology, do not appear to be skilled in using the Internet to do anything more than content searches. The techniques covered in the instruction which treated the Internet as a corpus and Google as a corpus search tool thus might be new to many students. Therefore, training in intelligent, language focused Google search strategies would be a useful way to foster the development and uptake of GALL by EAL university students, even for those who are (perhaps naively) assumed to be otherwise sophisticated Internet users.

Training appears to be a key factor in getting students to use GALL and concordancing. The importance of sufficient training has also been emphasised by other researchers in relation to concordancing (Gaskell \& Cobb, 2004; Kaur \& Hegelheimer, 2005; Liu \& Jiang, 2009). Nevertheless, students' unfamiliarity with concordancing is rather surprising. All participants in the present study would have previously had a significant amount of ESL or EFL instruction, so it is surprising that so few of them would have had any prior exposure to corpus-based language learning. Thus, even after at least a decade or more of the availability of corpora and concordancers, the use of these tools in second language classrooms still seems to be rare. On balance however, the novelty of concordancing and GALL, and students' existing use of these tools and techniques and interest in extending their use are good indications that university and pre-university students find these tools potentially useful for language development and academic writing. Thus, training in intelligent Google searching for language learning purposes would probably be enthusiastically received by students.

More research is required to find out precisely how students use Internet-based tools and techniques for language learning. One line of research would be to investigate which errors are amenable to correction by which method - GALL or concordancing or whether a combination of methods might be better (e.g., see Milton, 2006). Some researchers have already partially explored this area. Applying concordancing, Todd (2001, p.98) found for example that "although the numbers involved are small, they suggest that adjectives are easier than verbs, which in turn are easier than nouns, to induce patterns and to self-correct." Prepositions also seem to be an obvious choice for investigation (e.g. Yoon \& Hirvela, 2004) and a more focussed study would be helpful in this regard. Other specific areas of investigation are verb patterns and phrasal verbs, which Liu and Jiang (2009) suggest can be learned from corpus analysis.

The majority of studies so far have only looked at concordancing; very few have looked at GALL techniques. Therefore, given that EAL university students are already using GALL, it would be very useful to investigate how and why they use GALL. The findings might help inform the training for students by assessing what they already know and do. In fact, there are good reasons to believe that GALL might have 
advantages over concordancing for university students. For one thing, students are more familiar with Google and so do not need to learn a new interface.

Another important question is to what extent are online dictionaries useful in comparison to, or combination with, corpus-based methods. A small number of studies have begun to emerge in this area (e.g. Kaur \& Hegelheimer, 2005). Kaur and Hegelheimer (p. 298) emphasise that "the combined use of an online dictionary and concordancer continues to hold promise". A systematic study of the full range of Internet tools and techniques - concordancers, online dictionaries and Google - might thus shed light on what works best for whom and in what situations. Once again, the findings might help inform future training regimes for students by evaluating what combination of methods works best in what language learning situation.

The propensity for students to engage with GALL and concordancing might be a function of learning style. Unfamiliarity with inductive approaches to learning by some students (Sun, 2003) might have also been a factor in students' less than impressive performance in the error correction task in the present study. Many EAL Australian university students originate from countries in which inductive learning practices are relatively uncommon and so these students might not be familiar with data-driven approaches to language learning. This was perhaps one reason why two of the students who took part in the error correction task did not seem to engage properly with the task. These students might benefit from a more concerted effort at introducing them to corpus-based language learning techniques. One suggestion for training is that it is perhaps better for students to initially engage with more deductive learning before engaging with inductive approaches when independently using corpus-based tools and techniques (Liu \& Jiang, 2009). Alternatively, it could simply be the case that datadriven language learning is not for all students.

\section{Conclusion}

Internet-based corpus techniques offer a relatively new and under-used method for EAL university students to independently enhance their academic literacy and English language proficiency. At the moment however, this type of training appears to be either limited or unavailable in many Australian universities, who appear to have largely ignored these technologies. Thus, it appears that in Australian universities, training for EAL students who use, or want to use, concordancing and GALL techniques to support their L2 English writing and language development would be useful. Internet-based corpus language learning techniques could be one way to efficiently support the academic literacy needs of large numbers of EAL university students with limited numbers of language support staff. The challenge for university language support staff, other university educators and university administrators is how best to provide instruction in these tools and techniques to foster students' independent language learning.

\section{References}

Bhatia, T. K. \& Ritchie, W. C. (2009) Second language acquisition: Research and application in the information age. In W. C. Ritchie \& T. K. Bhatia (Eds.), The new handbook of second language acquisition (pp. 545-565). Bingley: Emerald.

Biggs, J. (2003). Teaching for quality learning at university: What the student does. Philadelphia: Society for Research into Higher Education and Open University Press. 
Birrell, B. (2006). Implications of low English standards among overseas students at Australian universities. People and Place, 14(4), 53-64.

Cargill, M. \& Adams, R. (2005). Learning discipline-specific research English for a world stage: A self-access concordancing tool? In Higher education in a changing world. Proceedings HERDSA Sydney 2005. http: / / conference.herdsa.org.au/2005/pdf/refereed/paper_202.pdf

Chambers, A. (2005). Integrating corpus consultation in language studies. Language Learning $\mathcal{E}$ Technology, 9(2), 111-125. http:/ /llt.msu.edu/vol9num2/chambers/ default.html

Chanock, K. (2007). Valuing individual consultations as input into other modes of teaching. Journal of Academic Language E Learning, 1(1), A1-A9. http: / / journal.aall.org.au/index.php/jall/article/view/1/4

Clerehan, R., Kett, G., \& Gedge, R. (2003). Web-based tools and instruction for developing it students' written communication skills. In Exploring educational technologies, 16-17 July, Monash University. [verified 18 Oct 2010; abstract only] http: / / www.monash.edu.au/groups/flt/ eet/ abstracts/D1-PM3-E1-Clerehan.pdf

Cobb, T. (1997). Is there any measurable learning from hands-on concordancing? System, 25 (3), 301-315.

Cobb, T. (1999). Applying constructivism: A test for the learner-as-scientist. Educational Technology Research \& Development, 47(3), 15-31.

Department of Employment Education and Workplace Relations (2008). Good practice principles for English language proficiency for international students in Australian universities. [verified 18 Oct 2010] http: / / www.deewr.gov.au/HigherEducation/Publications/Documents / Final_Report-Good_Practice_Principles.pdf

Dunworth, K. (2009a). An investigation into post-entry English language assessment in Australian universities. Journal of Academic Language \& Learning, 3(1), A1-A13. Retrieved October 8, 2009, from http:/ / journal.aall.org.au/index.php/jall/article/view / 67 / 57

Dunworth, K. (2009b). Meeting internal and external demands: the challenge of developing English language proficiency in an Australian university. Paper presented at the Australian Universities Quality Agency Forum: Higher Education, Alice Springs. [verified 18 Oct 2010; abstract only] http:/ / www.auqa.edu.au/files/auqf/abstract/paper_4.pdf

Ferris, D. (2002). The treatment of error in second language student writing. Ann Arbor: University of Michigan Press.

Fillmore, C. J. (2006). Frame semantics. In D. Geeraerts (Ed.), Cognitive linguistics: Basic readings (pp. 373-397). Berlin: Mouton de Gruyter.

Flowerdew, L. (2003). Corpus-based analyses in EAP. In J. Flowerdew (Ed.), Academic discourse (pp. 93-114). Harlow: Pearson.

Gaskell, D. \& Cobb, T. (2004). Can learners use concordance feedback for writing errors? System, $32,301-319$.

Guo, S. \& Zhang, G. (2007). Building a customised Google-based collocation collector to enhance language learning. British Journal of Educational Technology, 38(4), 747-750.

Hafner, C. A. \& Candlin, C. N (2007). Corpus tools as an affordance to learning in professional legal education. Journal of English for Academic Purposes, 6(4), 303-318.

Horst, M., Cobb, T. \& Nicolae, I. (2005). Expanding academic vocabulary with an interactive online database. Language Learning E Technology, 9(2), 90-110. http: / /llt.msu.edu/vol9num2/horst/ default.html

Huijser, H., Kimmins, L. \& Galligan, L. (2008). Evaluating individual teaching on the road to embedding academic skills. Journal of Academic Language $\mathcal{E}$ Learning, 2(1), A23-A38. http: / / journal.aall.org.au/index.php/jall/article/view/61/54 
Hutchings, C. (2006). Reaching students: Lessons from a writing centre. Higher Education Research and Development, 25(3), 247-261.

Johns, T. (1994). From printout to handout: Grammar and vocabulary teaching in the context of Data-driven Learning. In T. Odlin (Ed.), Perspective on pedagogical grammar (pp. 293-303). Cambridge: Cambridge University Press.

Kaur, J. \& Hegelheimer, V. (2005). ESL students' use of concordance in the transfer of academic word knowledge: An exploratory study. Computer Assisted Language Learning, 18(4), 287-310.

Lee, D. \& Swales, J. (2006). A corpus-based EAP course for NNS doctoral students: Moving from available specialized corpora to self-compiled corpora. English for Specific Purposes, 25, 56-75.

Liu, D. \& Jiang, P. (2009). Using a corpus-based lexicogrammatical approach to grammar instruction in EFL and ESL contexts. The Modern Language Journal, 93, 61-78.

Milton, J. (2006). Resource-rich Web-based feedback: Helping learners become independent writers. In K. Hyland \& F. Hyland (Eds.), Feedback in second language writing (pp. 123-139). New York: Cambridge University Press.

Mudraya, O. (2006). Engineering English: A lexical frequency instructional model. English for Specific Purposes, 25, 235-256.

Nation, P. (2001). Learning vocabulary in another language. Cambridge: Cambridge University Press.

O'Sullivan, I. \& Chambers, A. (2006). Learners' writing skills in French: Corpus consultation and learner evaluation. Journal of Second Language Writing, 15(1), 49-68.

Prince, P. (1996). Second language vocabulary learning: The role of context versus translations as a function of proficiency. The Modern Language Journal, 80(4), 478-493

Schmidt, N. (2000). Vocabulary in language teaching. New York: Cambridge University Press.

Shei, C. (2008a). Discovering the hidden treasure on the Internet: Using Google to uncover the veil of phraseology. Computer Assisted Language Learning, 21(1), 67-85.

Shei, C. (2008b). Web as corpus, Google, and TESOL: A new trilogy. Taiwan Journal of TESOL, 5(2), 1-28. [verified 18 Oct 2010] http: / / 137.44.46.192/ publication/ PublishedTaiwanTESOL2008.pdf

Stevenson, M. \& Kokkinn, B. (2007). Pinned to the margins? The contextual shaping of academic language and learning practice. Journal of Academic Language E Learning, 1(1), A44-A54. http: / / journal.aall.org.au/index.php/jall/article/view/38/29

Sun, Y.-C. (2003). Learning process, strategies and web-based concordancers: A case study. British Journal of Educational Technology, 34(5), 601-613.

Thursten, J. \& Candlin, C. N. (1998). Concordancing and the teaching of the vocabulary of academic English. English for Specific Purposes, 17(3), 267-280.

Todd, R. W. (2001). Induction from self-selected concordances and self-correction. System, 29, 91102.

University of South Australia (2007). English Language Proficiency Project. Unpublished report.

Yoon, H. \& Hirvela, A. (2004). ESL student attitudes toward corpus use in L2 writing. Journal of Second Language Writing, 13, 257-283.

\section{Mark A Conroy}

School of Behavioural, Cognitive and Social Sciences

University of New England, Armidale NSW 2351, Australia

Email: mconroy@une.edu.au 